\title{
A Simple Technique for Forming a Hand/Wrist Splint in an Uncooperative Child
}

\author{
L Mason, E Carpenter
}

\section{Citation}

L Mason, E Carpenter. A Simple Technique for Forming a Hand/Wrist Splint in an Uncooperative Child. The Internet Journal of Orthopedic Surgery. 2008 Volume 11 Number 1.

\section{DOI: $\underline{10.5580 / 1 \mathrm{~d} 1 \mathrm{~b}}$}

\begin{abstract}
A child with an injury is usually upset and uncooperative. It is therefore challenging to mold an adequate light weight splint for hand or wrist injuries. The more you endeavor to achieve a suitable result, the more the distressed the child will get and the more likely you will achieve a soft malformed splint. We present a quick and useful technique to mold a plaster on a child which maintains its position until the plaster sets.
\end{abstract}

\section{TECHNIQUE}

1. Measure the diameter of the patient's wrist and the distance from the distal inter-phalangeal joint (IPJ) of middle finger to two finger breadths from the elbow crease. Choose a Zimmer® splint that is at least $50 \%$ the diameter of the childs wrist and cut it to length. Trim sharp edges.

2. Apply layer of wool from tips of fingers to elbow crease.

3. Cut 4 ply Gypsona ${ }^{\circledR}$ plaster to length. Fold it in half over the splint.

4. Place Zimmer® splint with rubber facing up, on the Plaster, and place in stockinet (Appropriately sized Delta Terry-Net ${ })$.

5. Dip the stockinet in warm water and mold into Edinburgh position (wrist - ext/neutral, MCPJ $90^{\circ}$ flexion, IPJ - extension).

6. Bandage

\section{DISCUSSION}

We find that the Zimmer splint molds easily and quickly into the required position and keeps it in that position to allow hardening of the plaster. In our experience this has provided excellent results. The plaster is light weight, durable, quick, and easily removable making it the ideal alternative to advanced splinting. It is a temporary splint, and used for occasions where immobilisation of the upper limb will provide comfort and pain relief. We have used this technique on 50 patients up to date of submission without any adverse consequences. Indications for such a splint include hand injuries including tendon and nerve prior to repair, wrist injuries and distal radius/ulna fractures.

\section{Figure 1}

Figure 1: An example of the splint in an uncooperative child

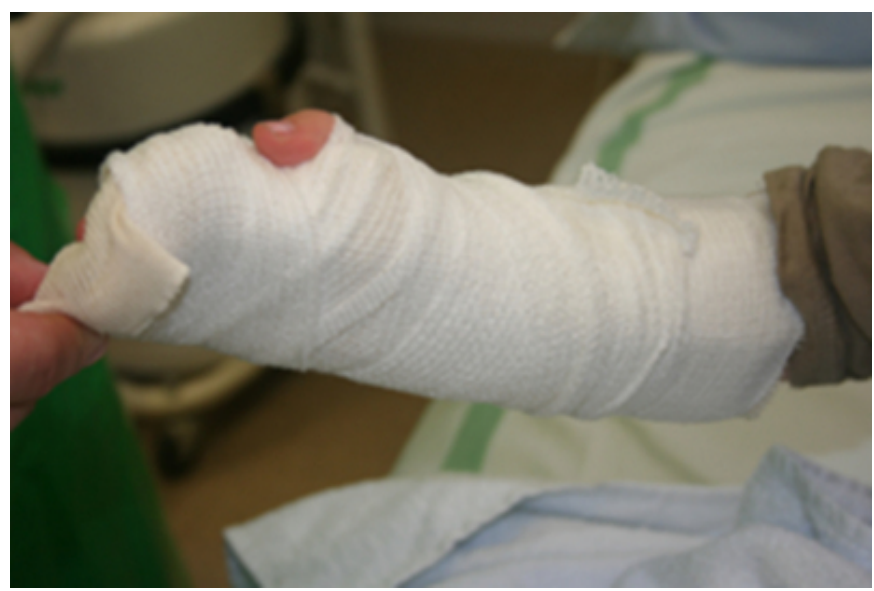

\section{CORRESPONDENCE TO}

Mr Lyndon William Mason 2 Pantbach Avenue, Rhiwbina, Cardiff, CF14 1UR E-mail: drlyndonmason@doctors.org.uk Telephone: 07947038874

\section{References}




\section{Author Information}

Lyndon W. Mason, MRCS

Specialist Registrar, Trauma and Orthopaedic Department, Wrexham Maelar Hospital

Eleanor C. Carpenter, MRCS

Specialist Registrar, Trauma and Orthopaedic Department, Royal Glamorgan Hospital 